\title{
Impact of Sensory Adapted Dental Environment on Children with Developmental Disabilities
}

Gail Kim

Follow this and additional works at: https://scholarscompass.vcu.edu/etd

Part of the Pediatric Dentistry and Pedodontics Commons

(C) The Author

\section{Downloaded from}

https://scholarscompass.vcu.edu/etd/5295

This Thesis is brought to you for free and open access by the Graduate School at VCU Scholars Compass. It has been accepted for inclusion in Theses and Dissertations by an authorized administrator of VCU Scholars Compass.

For more information, please contact libcompass@vcu.edu. 
Gail Kim

2018

All Rights Reserved 


\title{
Impact of Sensory Adapted Dental Environment on Children with Developmental
}

\section{Disabilities}

\author{
A thesis submitted in partial fulfillment of the requirements for the degree of Master of Science \\ in Dentistry at Virginia Commonwealth University.
}

By

\section{Gail Kim, DMD}

BS, University of Pittsburgh, 2008

DMD, University of Pittsburgh School of Dental Medicine, 2016

Thesis Advisor: Patrice Wunsch, DDS, MS

Associate Professor, Department of Pediatric Dentistry

Virginia Commonwealth University

Richmond, Virginia

May 2018 


\section{Acknowledgement}

This research project would not have been possible without the financial support of the Alexander Fellowship Grant. I would like to thank my thesis advisor, Dr. Patrice Wunch, for her support and direction with the project. I would also like to thank Dr. Carrico for always going out of her ways to help me with the research. My sincere appreciation also goes to Dr. Carole Ivey, who has provided me with the tools and knowledge to expand my understanding of the study topic. I graciously thank Dr. Berry, Program Director and Research Committee for supporting my research and accommodating clinic schedule for the research time.

Last but not least, I would like to show my gratitude to my family for their endless support, dedication and love. I would not have made it to where I am today if it were not for them. 


\section{Table of Contents}

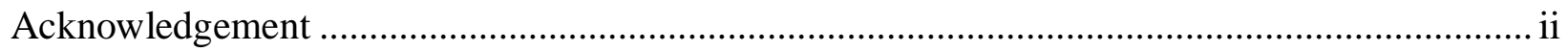

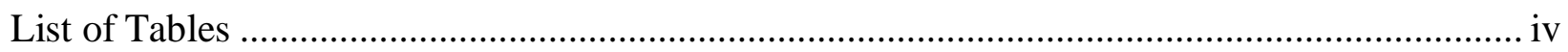

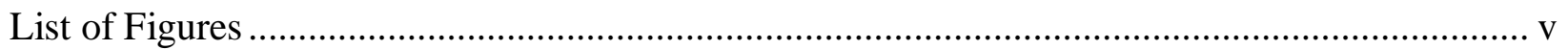

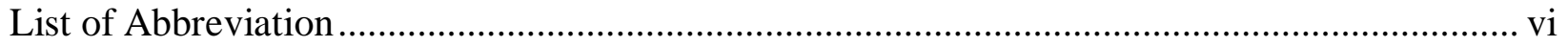

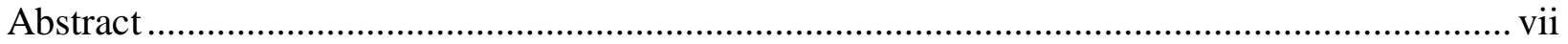

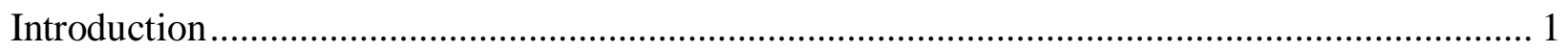

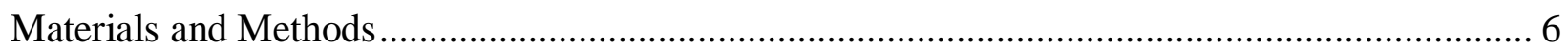

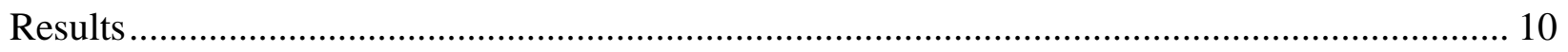

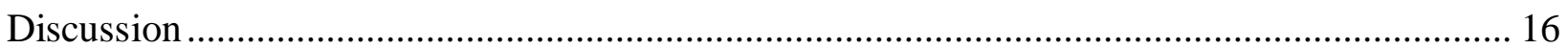

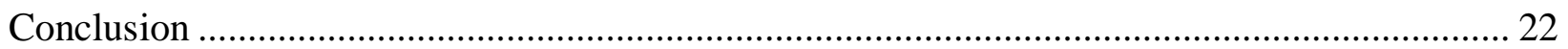

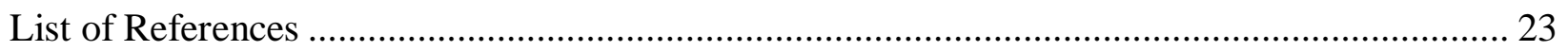

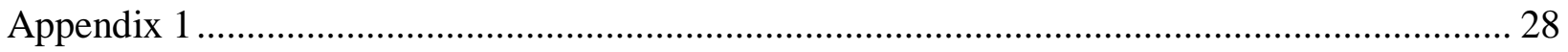

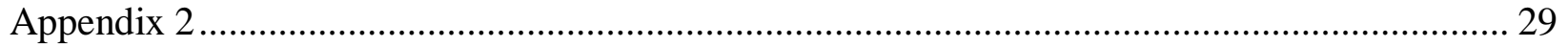

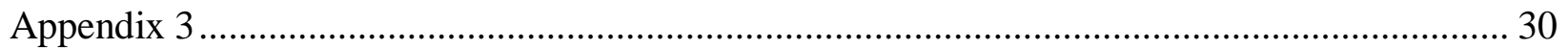

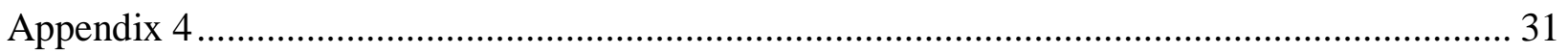




\section{List of Tables}

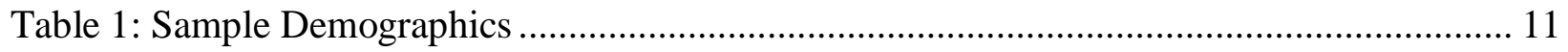

Table 2: Characteristics of Study Subjects including Sensory Profile .................................... 12

Table 3: Median Study Outcome Measures by Treatment Setting ........................................ 13

Table 4: Repeated Measures ANOVA Results for Covariates of Interest .................................. 14 


\section{List of Figures}

Figure 1: Frankl Score and Modified Frank1 Score ......................................................... 8

Figure 2: Summary of Responses to Parent/Caregiver Questionnaire After Both Visits ............. 15 


\section{List of Abbreviation}

$\begin{array}{ll}\text { ASD } & \text { Autism Spectrum Disorder } \\ \text { CP } & \text { Cerebral Palsy } \\ \text { DD } & \text { Developmental Disabilities } \\ \text { ID } & \text { Intellectual Disabilities } \\ \text { I/DD } & \text { Intellectual/Developmental Disabilities } \\ \text { NDD } & \text { Neurodevelopmental Disorder } \\ \text { SADE } & \text { Sensory Adapted Dental Environment } \\ \text { RDE } & \text { Regular Dental Environment }\end{array}$




\begin{abstract}
IMPACT OF SENSORY ADAPTED DENTAL ENVIRIONMENT ON CHILDREN WITH DEVELOPMENTAL DISABILITIES
\end{abstract}

By Gail Kim, DMD.

A thesis submitted in partial fulfillment of the requirements for the degree of Master of Science at Virginia Commonwealth University.

Virginia Commonwealth University, 2018.

Major Director: Dr. Patrice Wunsch, DDS, MS

Associate Professor, Department of Pediatric Dentistry

Purpose: This was a pilot study assessing the impact of a sensory adapted dental environment (SADE) on children with developmental disabilities (DD) receiving routine dental care.

Methods: A crossover study of 22 children with DD, aged 6 through 21, was conducted at Virginia Commonwealth University Pediatric Dental clinic. Each participant was randomized to a sequence of two dental cleanings, one regular dental environment (RDE) and one SADE with a 3-4-month recall. Outcomes included physiological measures (heart rate and oxygen saturation) and cooperation (Frankl scores). 
Results: Study subjects completed a total of 36 visits. None of the physiological measures differed at either time point between the two treatment settings. The Frankl scores were significantly higher with $\mathrm{SADE}$ setting than $\mathrm{RDE}$ ( $p=0.0368$ ). Forty-six percent of parents strongly agreed that they would prefer the SADE for their child's next visit.

Conclusion: SADE may be associated with improved behavior in children with DD. 


\section{Introduction}

The number of children with developmental disabilities (DD) has increased dramatically since 1990s. The CDC reported children with developmental disabilities have increased $17.1 \%$ from 1997 to 2008. Recent estimates in the United States show that about one in six, or about $15 \%$ of children aged 3 through 17 years have one or more developmental disabilities. ${ }^{1}$ Developmental disabilities, also known as neurodevelopmental disorders, are a diverse group of chronic conditions that are due to mental and/or physical impairments. Children with DD experience challenges such as language, mobility, learning, self-help, and independent living. Under this broad spectrum of disability, individuals with DD may have intellectual disabilities (ID), communication disorders, Autism Spectrum Disorder (ASD), Attention-Deficit/Hyperactivity Disorder (ADHD), specific learning disorders, motor disorders, and other neurodevelopmental disorders. $^{2}$

Previous studies have shown that the rate of unmet oral health needs is higher in individuals with DD compared with the general population. ${ }^{3-6}$ Despite the growing number of children with disabilities living longer and healthier lives with medical advancements, it is a constant challenge for individuals with DD to receive comprehensive dental care. Multiple barriers have been identified: (1) residential effect, which promotes a community-based living to improve quality-of-life for individuals with DD without any parallel effort to ensure that there is a comprehensive and consistent health care system readily available for this vulnerable 
population; (2) a lack of trained clinicians who can accommodate the special health care needs of DD;(3) challenging behaviors characteristic to this population. ${ }^{4-13}$

Nelson et al. divided barriers to oral health care into two groups, environmental and nonenvironmental. Environmental barriers, which originate in the dental care system, include cost of care, getting appointments, physical accessibility, and lack of training of dental team. Nonenvironmental barriers, which originate with the child and family, include child's behavior, fear of dentists, and competing medical demands. In this survey, $20 \%$ of parents of children with special health care needs reported that their child had an unmet dental need. Also, children with cerebral palsy, ASD, developmental delay, and Down syndrome had more aversions to dental treatment, more treatment complications posted by their medical conditions, and more difficulty finding a dentist willing to provide care compared to that of children with other special health care needs. ${ }^{6}$

A dental appointment can be especially difficult for children with DD due to the child's limited ability to comprehend the goal of the dental appointment, oral aversion corresponding to their medical diagnosis, the unfamiliarity of the dental environment, and sensitivity to sensory stimuli presented in a regular dental setting (high-speed hand piece, prophylaxis angle, overhead light, loud ambient noises, texture and taste of prophylaxis paste). ${ }^{14-18}$ In a study evaluating potential predictors of cooperation during dental appointments for children with autism, $65 \%$ of patients with ASD had uncooperative behavior, with only $35 \%$ being cooperative. ${ }^{19}$ In another study assessing the oral care and sensory issues in children with ASD, significantly more parents of children with ASD rated their child's experience as "negative" and reported that it was "moderately to extremely" difficult to have the dentist or hygienist clean their child's teeth. In the same survey of parents of child with ASD, $69 \%$ of parents reported that the dental visit is 
more stressful for their child with ASD compared to that of other siblings. ${ }^{15}$ In another survey of parents of children with special healthcare needs, approximately $50 \%$ of parents believed that sensory processing difficulties interfered with their child's oral care in the dental office. ${ }^{14}$

Current estimates indicate that more than $80 \%$ of children with ASD exhibit concurrent sensory processing problems. ${ }^{20}$ Sensory processing difficulties may be one of the contributing factors to poor cooperation in the dental office for children with ASD. When such problems are present, responses to incoming sensory stimuli are not graded adequately, leading to an over- or under-reaction to stimulation. ${ }^{14}$ Subsequently, children with ASD can respond atypically to visual, auditory, tactile, olfactory, or gustatory stimuli. In a regular dental environment, children with ASD are bombarded with sensory stimuli which could negatively impact their behavior and level of cooperation for routine dental visits. Sensory processing difficulties have been analyzed using the sensory integration theory introduced by an occupational therapist, A. Jean Ayres, in the 1970s. This theory refers to the body's way of handling and processing sensory inputs from the environment. Ayres postulated that individuals with sensory dysfunction experience impaired sensory systems and neurological processing of sensory information, which negatively affect development and learning. ${ }^{21}$

Based on Ayres' sensory integration theory, sensory-based treatment has been studied and utilized by occupational therapists and other health professionals in treating individuals with DD. Sensory-based treatments are designed to provide individualized, controlled sensory experiences to help modulate responses to environmental inputs. These activities include a variety of sensory modalities such as vestibular, touch, and auditory, targeting hyper- or hyposensitivities. The primary goals of sensory-based treatments are to improve sensory processing and self-regulation, to increase adaptive function, and to help the child participate in daily 
activities. However, there is not a universally accepted protocol for implementing sensory-based treatment. A number of systematic reviews of sensory-based treatments show limited or inconclusive empirical support. The efficacy of sensory integration therapy is yet to be conclusive because it is unclear whether children who present with sensory-based problems have a distinct sensory dysfunction or that these deficits are characteristics associated with DD.22

In the dental field, sensory-based treatment has been studied as a novel intervention to reduce dental anxiety of children. Shapiro et al. studied 19 typically developing children, aged 611 year, who participated in a cross-over intervention trial. The SADE was created by modifying visual, tactile, somatosensory, and auditory stimuli. Behavioral parameters included the mean number, duration, and magnitude of anxious behaviors recorded by observing the participants' negative dental behavior (head movements, eye movements, mouth movements, forehead movement, coughs/gag reflex, crying/screaming, and others). Physiological parameters reflecting the level of arousal included the changes in dermal resistance. All measures consistently indicated that both behavioral and psychophysiological measures of relaxation improved significantly in the SADE compared with a conventional dental environment. ${ }^{23}$ In 2009 , Shapiro et al. applied the same sensory-based treatment on 16 children with DD. This was the first study observing the efficacy of sensory-based treatment on anxiety of children with DD in a dental setting. ${ }^{24}$ The result from this study correlated with the results from the typically developing children, but the effect was smaller. The findings from this study indicated the potential importance of considering the sensory-adapted environment as a preferable dental environment for the children with DD. A similar pilot study by Cermak et al. examined the efficacy of SADE on children with autism. This study yielded results that supported the previous studies' findings. ${ }^{25}$ 
The purpose of this pilot study was to gather data on the effect of SADE on behavioral outcomes and physiological changes in the children with DD, compared to that of a RDE. We hypothesized that (1) the participants' behavior during a routine dental care visit with SADE would be better compared to that of a RDE; (2) the physiological outcomes will be different in the SADE compared to the RDE; (3) parents of the participants will favor dental treatment under the SADE. The study presents adopting a sensory modified intervention in a dental setting to improve the dental experience of this vulnerable population. 


\section{Materials and Methods}

The Institutional Review Board at Virginia Commonwealth University, Richmond, VA., USA, approved this pilot study evaluating the impact of the SADE on children's behavior during routine dental exam and cleaning (Protocol Number: HM20009272). This was an experimental crossover design in which each participant was randomly assigned to a RDE or a SADE for his/her new patient exam or a recall exam (Phase I) and was asked to return for a 3-month recall (Phase II) which would be executed with the remaining environment. The study sample included children aged between 6 and 21 who have been diagnosed with DD, visiting VCU Pediatric Dental Clinic for oral health care between July 2017 and December 2017. Target participants with DD had neurodevelopmental disabilities including, but not limited to, Down syndrome, Autism Spectrum Disorder, cerebral palsy, developmental delay, and any disabilities associated with chromosomal disorders. The exclusion criteria included non-English speakers.

All parents or legal guardians of the target children were invited by the student investigator to participate on the day of their child's dental appointment. Participation in this study was voluntary and the parents or legal guardians of the subjects were informed that they could withdraw from the study at any time. No incentives were given for participation in the study.

The SADE was created by modifying sensory stimuli that are normally presented in a typical dental setting. For visual sensory modification, solar projector (Cloud B Tranquil Turtle Night Light, CB-7423PR) and practitioner's overhead light (Q-Optics, Radiant LED Headlight, 
Duncanville, Tx) were the only lights on in a quiet room. A regular X-ray lead apron was laid on each patient for proprioceptive stimuli, and calming nature sound (Calming Seas \#1 - 11 Hours Ocean Waves Sound) was played in the background. The proprioceptive stimuli from the X-ray lead apron was aimed for providing deep pressure input to produce a calming effect. ${ }^{26}$

Parents/guardians of participants completed a basic demographic survey and sensory profile. The demographic survey included the patient's age, gender, race/ethnicity, and parents' education level. The Short Sensory Profile is a frequently used screening tool with high validity for assessing sensory processing in children. ${ }^{27}$ It is a 34 -item parent reported questionnaire standardized for children ages 3 through 14 years. The questionnaire uses a 5-point Likert scale for parents to report how frequently their child responds to sensory input in their daily activities. The purchase, scoring, and interpretation of the Short Sensory Profile were completed under supervision of a licensed occupational therapist.

During the exam and cleaning, an additional provider (pediatric dental resident) was present in the room to record the Frankl behavior score for each patient. The Frankl Scale is a one-item dentist-reported scoring of children's behavior in the dental environment. ${ }^{28}$ It uses 4-point Likert Scale ranging: 1 (definitely negative), 2(negative), 3 (positive), 4 (definitely positive) and has high inter-rater reliability and moderate validity. ${ }^{29}$ The traditional description of Frankl behavior measurement was modified for this study to accommodate the unique characteristics of the participants' disabilities (Figure 1).

All pediatric dentistry residents were calibrated for consistent scoring of Frankl behavior scale prior to the initiation of the study. The differences in scoring during the calibration were discussed in detail to achieve consistency. During the study, two raters scored each patient and the interrater reliability was assessed using Cohen's Kappa statistic. Physiologic outcomes such 
as oxygen saturation and heart rate were recorded at the beginning and at the end of the appointment with a pulse oximeter (Nellcor ${ }^{\mathrm{TM}}$ Covidien, Boulder, CO). Participants were asked to return for 3-month recall exam under either a RDE or SADE (Phase II) depending on the treatment received at the initial visit. Parents/caregivers completed the post-treatment survey to assess cooperation of their child in RDE compared to SADE.

Sample demographic data was summarized using descriptive statistics. Paired analysis on physiologic outcomes and behavior scores was performed with Wilcoxon Signed Rank- Sum test for subjects who completed both visits. Repeated measures ANOVA models using all study visits were constructed to test for differences based on treatment setting while considering other covariates of interest. Post hoc pairwise comparisons were analyzed using Tukey's HSD to adjust for multiple comparisons. All analyses were performed in SAS EG v.6.1 with a significance level of 0.05 . 
Figure 1: Frankl Score and Modified Frankl Score

\begin{tabular}{|c|c|c|c|}
\hline & & Standard Description & Modified Description \\
\hline 1 & -- & $\begin{array}{l}\text { Definitely negative. Refusal of } \\
\text { treatment, forceful crying, fearfulness, } \\
\text { or any other overt evidence of extreme } \\
\text { negativism. }\end{array}$ & $\begin{array}{l}\text { - Movement, pacing around the room, unable to } \\
\text { sit in the dental chair; excessive head/hand } \\
\text { movements } \\
\text { - Inconsolable screaming and crying, verbal } \\
\text { protest } \\
\text { - Self-injurious behavior (can range from gentle } \\
\text { patting to aggressive hitting and biting) } \\
\text { - Unable to complete an exam/cleaning }\end{array}$ \\
\hline 2 & - & $\begin{array}{l}\text { Negative. Reluctance to accept } \\
\text { treatment, uncooperative, some } \\
\text { evidence of negative attitude but not } \\
\text { pronounced (sullen, withdrawn). }\end{array}$ & $\begin{array}{l}\text { - Movement, pacing around the room but } \\
\text { eventually sits in the chair with lots of TSD; } \\
\text { head and hand movement that may interfere } \\
\text { with the exam/cleaning } \\
\text { - Mild screaming and crying, verbal protest } \\
\text { - Self-injurious behavior } \\
\text { - } \text { Allow for limited dental exam /cleaning }\end{array}$ \\
\hline 3 & + & $\begin{array}{l}\text { Positive. Acceptance of treatment; } \\
\text { cautious behavior at times; willingness } \\
\text { to comply with the dentist, at times } \\
\text { with reservation, but patient follows the } \\
\text { dentist's direction cooperatively. }\end{array}$ & $\begin{array}{l}\text { - Minimal movement of head, hands remain } \\
\text { down or partially raised to signal discomfort. } \\
\text { - Tense facial expression, may have tears in eyes } \\
\text { - No self-injurious behavior } \\
\text { - Allow for a through exam/cleaning }\end{array}$ \\
\hline 4 & ++ & $\begin{array}{l}\text { Definitely positive. Good rapport with } \\
\text { the dentist, interest in the dental } \\
\text { procedures, laughter and enjoyment. }\end{array}$ & $\begin{array}{l}\text { - No movement; hands remain down } \\
\text { - No self-injurious behavior } \\
\text { - Allow for a through exam/cleaning }\end{array}$ \\
\hline
\end{tabular}




\section{Results}

A total of 22 patients were enrolled in the study. Demographics are given in Table 1. Sixty-two percent were male, $41 \%$ were aged 6-10 years old, and the most common diagnosis was ASD (38\%). Seventy-one percent had history of dental general anesthesia and $24 \%$ had history of use of papoose for dental treatment. Table 2 includes baseline sensory characteristics of the study participants. More than half of the participants were non-verbal (60\%) and $70 \%$ presented with probable sensory modulation disorder. Results from the Short Sensory Profile are also given in Table 2. 
Table 1: Sample Demographics

\begin{tabular}{|c|c|c|}
\hline & $\mathbf{n}$ & $\%$ \\
\hline \multicolumn{3}{|l|}{ Age } \\
\hline $6-10$ & 9 & $41 \%$ \\
\hline $11-15$ & 6 & $27 \%$ \\
\hline $16-21$ & 7 & $32 \%$ \\
\hline \multicolumn{3}{|l|}{ Gender } \\
\hline Male & 14 & $64 \%$ \\
\hline Female & 8 & $36 \%$ \\
\hline \multicolumn{3}{|l|}{ Parent Education Level } \\
\hline Less than High School/GED & 3 & $14 \%$ \\
\hline High School/GED & 8 & $38 \%$ \\
\hline Some College & 1 & $5 \%$ \\
\hline Associate Degree & 5 & $24 \%$ \\
\hline College Graduate & 3 & $14 \%$ \\
\hline More than College & 1 & $5 \%$ \\
\hline \multicolumn{3}{|l|}{ History of GA } \\
\hline Yes & 15 & $71 \%$ \\
\hline No & 6 & $29 \%$ \\
\hline \multicolumn{3}{|l|}{ Papoose Use } \\
\hline Yes & 5 & $24 \%$ \\
\hline No & 16 & $76 \%$ \\
\hline \multicolumn{3}{|l|}{ Treatment Order } \\
\hline SADE-Normal & 13 & $59 \%$ \\
\hline $\begin{array}{ll}\text { Normal-SADE }\end{array}$ & 9 & $41 \%$ \\
\hline \multicolumn{3}{|l|}{ Primary Diagnosis (Check all that apply) } \\
\hline Intellectual Disability (Mental Disability) & 3 & $9 \%$ \\
\hline Autism Spectrum Disorder & 13 & $38 \%$ \\
\hline Cerebral Palsy & 2 & $6 \%$ \\
\hline Down Syndrome & 4 & $12 \%$ \\
\hline Developmental Delay/Disability & 4 & $12 \%$ \\
\hline \multicolumn{3}{|l|}{ Attention Deficit/Hyperactivity Disorder } \\
\hline (ADHD) & 3 & $9 \%$ \\
\hline Other & 5 & $15 \%$ \\
\hline
\end{tabular}


Table 2: Characteristics of Study Subjects including Sensory Profile

\begin{tabular}{|c|c|c|}
\hline & $\mathbf{n}$ & $\%$ \\
\hline \multicolumn{3}{|l|}{ Verbal } \\
\hline Verbal & 9 & $43 \%$ \\
\hline Non-verbal & 12 & $57 \%$ \\
\hline \multicolumn{3}{|l|}{ Sensory Modulation Disorder } \\
\hline Yes & 15 & $71 \%$ \\
\hline No & 6 & $29 \%$ \\
\hline \multirow{2}{*}{\multicolumn{3}{|c|}{ Sensory Profile }} \\
\hline & & Sensory \\
\hline Less Than/Like Others & 7 & $33 \%$ \\
\hline More Than/Much More Than & 14 & $67 \%$ \\
\hline \multicolumn{3}{|l|}{ Behavioral } \\
\hline Less Than/Like Others & 6 & $29 \%$ \\
\hline More Than/Much More Than & 15 & $71 \%$ \\
\hline \multicolumn{3}{|l|}{ Seeker } \\
\hline Less Than/Like Others & 7 & $33 \%$ \\
\hline More Than/Much More Than & 14 & $67 \%$ \\
\hline \multicolumn{3}{|l|}{ Avoider } \\
\hline Less Than/Like Others & 5 & $24 \%$ \\
\hline More Than/Much More Than & 16 & $76 \%$ \\
\hline \multicolumn{3}{|l|}{ Sensory Sensitivity } \\
\hline Less Than/Like Others & 5 & $24 \%$ \\
\hline More Than/Much More Than & 16 & $76 \%$ \\
\hline \multicolumn{3}{|l|}{ Registration } \\
\hline Less Than/Like Others & 11 & $52 \%$ \\
\hline More Than/Much More Than & 10 & $48 \%$ \\
\hline
\end{tabular}

Study subjects completed a total of 36 visits resulting in a loss to follow-up rate of $36 \%$. There was no difference in participant age $(p$-value $=0.1426)$, gender $(p$-value $=0.1673)$, treatment order $(p$-value $=0.1870)$, verbal/non-verbal status $(p$-value $=0.3972)$, or sensory modulation disorder $(p$-value $=0.3544)$ between those who completed both visits and those who were lost to follow-up. Inter-rater agreement on Frankl scores was high $(\kappa=0.8354)$. 
The median difference in Frankl scores was 1, favoring better behavior in SADE than RDE ( $p$-value $=0.0703$ for clinician's Frankl scores and $p$-value $=0.1094$ for independent observer). None of the physiological measures differed at either time point (pre or post) between the two treatment settings (Table 3).

Table 3: Median Study Outcome Measures by Treatment Setting

\begin{tabular}{|lrrrrr|}
\hline \multirow{2}{*}{ Heart Rate } & & SADE & RDE & $\begin{array}{r}\text { Paired } \\
\text { Difference }\end{array}$ & P-value \\
& & & & & \\
& Pre & 92 & 94 & 0.00 & 0.9863 \\
Oxygen & Post & 100.5 & 99 & -2.00 & 0.8135 \\
Saturation & & & & & \\
& Pre & 0.99 & 0.99 & 0.00 & 1.0000 \\
Frankl & Post & 0.99 & 0.99 & 0.00 & 0.8594 \\
& & & & & \\
& Clinician & 3 & 2 & 0.50 & 0.0703 \\
& Observer & 3 & 2 & 1.00 & 0.1094 \\
\hline
\end{tabular}

Due to the high loss to follow-up rate, an unpaired analysis was also performed to take advantage of data from all patient visits, while still adjusting for correlation between Frankl scores for subjects with multiple visits. When comparing all visits with repeated measures ANOVA, observer Frankl scores were significantly higher with SADE setting than RDE (average difference $=0.443 ; p$-value $=0.0368$ ). Results were similar when using clinician's Frank1 scores (average difference $=0.435 ; p$-value $=0.0182$ ).

Covariates of interest were also included in repeated measures ANOVA model to determine if there were any factors associated with Frankl scores. Factors evaluated included: treatment order, age, gender, sensory modulation disorder, all subscores of the Sensory Profile, primary diagnosis of ASD, history of dental general anesthesia, history of papoose use, and whether or not the patient was verbal (Table 4). There was evidence of a difference in observer's 
Frankl Scores based on the patient's verbal abilities $(p$-value $=0.0435)$, patient age $(p$ value $=0.0841)$, and history of papoose use $(p$-value $=0.0314)$. Specifically, non-verbal patients had lower Frankl scores on average (2.51 vs 3.24), 6-10 years old subjects had lower Frankl scores than the two older groups (2.4 for 6-10 vs 3.14 for 16-21years old and 3.18 for 11-15years old), and those with history of papoose use had lower average Frankl scores (2.1 vs 3.0). The interaction terms between treatment setting (RDE, SADE) and each of these covariates were not statistically significant, indicating the dental environment does not have a different effect based on these factors.

Table 4: Repeated Measures ANOVA Results for Covariates of Interest

\begin{tabular}{|lrr|}
\hline \multicolumn{2}{|c|}{$\begin{array}{l}\text { Association with Observer } \\
\text { Frankl }\end{array}$} & Interaction \\
\hline Treatment Order & 0.3725 & \\
Age & 0.0841 & 0.753 \\
Gender & 0.1936 & \\
Sensory Modulation Disorder & 0.9776 & \\
Sensory Profile Subscores & & \\
Sensory & 0.7523 & \\
Behavioral & 0.5543 & \\
Seeker & 0.9342 & \\
Avoider & 0.4000 & \\
Sensory Sensitivity & 0.4000 & \\
Primary Diagnosis of ASD & 0.8347 & \\
History of GA & 0.6897 & \\
History of Papoose & 0.2633 & \\
Verbal/Nonverbal & 0.0314 & 0.3865 \\
\hline
\end{tabular}

Results from parents and guardians of the study subjects who completed both visits are given in Figure 2. None of the respondents disagreed or strongly disagreed with any of the statements which favored SADE over RDE. Fifty-four percent of respondents strongly agreed that the 
SADE improved their child's dental anxiety during the routine dental exam and cleaning, and $46 \%$ strongly agreed that they would prefer the SADE for their child's next visit.

Figure 2: Summary of Responses to Parent/Caregiver Questionnaire After Both Visits

I would prefer my child to receive dental exam under SADE instead of a regular dental environment for my child's next visit.

My child did better cooperating for dental exam and cleaning in the SADE compared to his/her previous dental exams and cleanings.

The SADE improved my child's cooperation for the routine dental exam and cleaning.

The Sensory Adapted Dental Environment (SADE) improved my child's dental anxiety during the routine dental exam and cleaning.
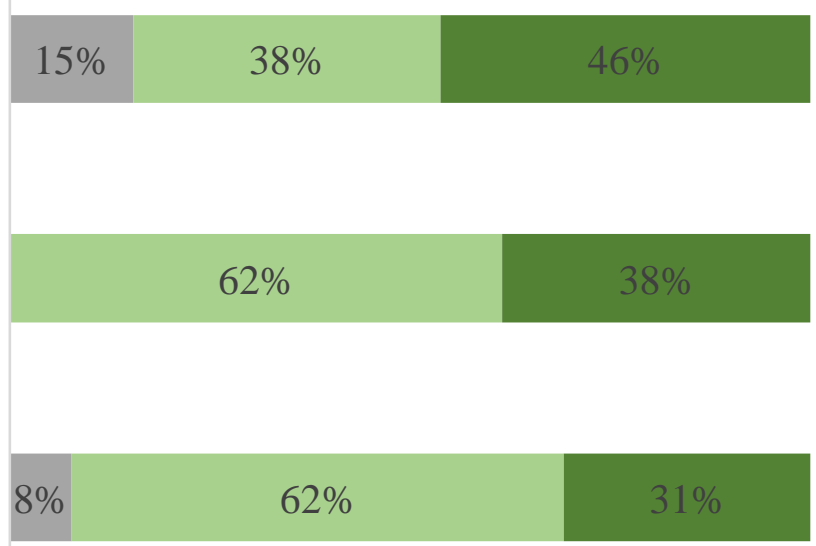

\section{$46 \%$}

$25 \%$

$50 \%$

$75 \%$

$100 \%$

$\square$ Neutral $\square$ Agree $\square$ Strongly Agree 


\section{Discussion}

This pilot study suggests that SADE has a positive impact on the behavior of children with DD undergoing routine dental treatment. The Frankl behavior score of the 36 completed visits indicate that SADE resulted in significantly higher Frankl scores compared to that of a RDE ( $p$ value $=0.0368$ ). The Frankl behavior score of the paired result were not statistically significant at the 0.05 level but were all below the 0.10 significance level, which is often used for preliminary results with pilot studies. Of the 14 who completed both visits, $8(57 \%)$ had higher observer Frankl score with SADE, 4 (29\%) had no change in Frankl score, and 2 (14\%) had lower Frankl score with SADE. This supports our first hypothesis that the cooperation of children with DD under SADE would be better than compared to that of a RDE. Our findings on improved behavior under SADE are consistent with the previous studies presented by Shapiro et al and

Cermak et al. ${ }^{23-25}$ A recent systematic review of specific sensory techniques and sensory environmental modifications for children with sensory integration difficulties concluded that there is moderate evidence supporting the use of SADE. ${ }^{30}$

Our second hypothesis stating that there would be a difference in the physiological outcomes of the children with DD undergoing SADE or RDE was inconclusive. The participants' heart rate and oxygen saturation were recorded in the beginning and at the end of each visit to collect objective data reflecting on their physiological distress during a dental appointment. Neither unpaired or paired analyses revealed any significant difference in the heart rate or oxygen saturation. Our data on the participants' physiological distress was not a good 
representation of their level of cooperation during either treatment intervention, SADE or RDE. The measurement of heart rate and oxygen saturation with a pulse oximeter was challenging for many of participants. Participants had a difficult time holding their hands still for an accurate reading, and the time it took to obtain the measurement varied from participant to participant.

The third hypothesis of the study postulated that the parents and guardians of the participants will favor the sensory-based treatment over the conventional dental treatment. The results strongly supported our hypothesis. Not only did the parents agree that the SADE improved their child's dental anxiety and cooperation during a routine dental exam and cleaning but, they also reported that their child's cooperation was better under a SADE compared to a dental treatment under a RDE. Eighty five percent of the parents reported that they would prefer the SADE for their child's next dental visit (38\% agree and $46 \%$ strongly agree). The parents of children with DD are the best advocates for their children; they often help with bridging the communication gap between providers and their children given that these children may not have the ability to communicate their discomfort and dental distress. The agreement to applying the SADE during a dental visit reported by the parents in our study could indicate that the SADE indeed assists in maximizing relaxation and reducing sensory stimuli. It could also indicate the parents' appreciation for the extra effort initiated by the clinician to provide a more enjoyable dental experience of their child.

One of the goals of the SADE is to provide a positive dental experience for the children with DD. Our data support that the SADE, compared to a RDE, may increase the level of patient cooperation during routine dental appointment. Additional studies should be conducted to confirm that the SADE could be used as a practical tool for the clinicians to apply in their daily routine for treating the children with DD. One of the biggest barriers identified among general 
dentists (60\% of respondents) was patient behavior. ${ }^{10}$ Through the use of SADE and an improved patient cooperation level, clinicians may gain confidence in treating children with DD.

Future studies need to focus on the behavioral guidance driven by individual patient's sensory profile. The American Academy of Pediatric Dentistry recommends traditional behavioral guidance such as communication guidance, positive pre-visit imagery, direct observation, ask-tell-ask, voice control, Tell-Show-Do, non-verbal communication, positive reinforcement and descriptive praise, distraction, and nitrous sedation to guide children throughout the dental treatment and to help build their coping skills. ${ }^{31}$ However, these strategies are often not sufficient to engage children with DD for exam and cleaning visits due to deficits that are uniquely associated with their disabilities. Moreover, the physical and psychological impairments, including sensory processing difficulty, make cooperation and tolerance to dental treatment even more difficult for children with DD. Sensory-based interventions and sensory integration therapy have been used in occupational therapy to improve children's functions of daily life and to develop adaptive responses to the child's sensory processing and motor planning skills. ${ }^{22,32,33}$ The systematic review on sensory-based interventions concluded that there is limited evidence to support the use of sensory-based interventions on improving behavior in children. However, these studies often used a single-sensory strategy (e.g., a weighted vest) or they did not follow specific protocols. ${ }^{33}$ Despite the limitations, the use of sensory-based intervention in a dental setting has shown promising results and should be investigated further. ${ }^{23-25}$ By modifying sensory stimuli posed by a conventional dental environment, findings in our study along with the results of other pilot studies ${ }^{23-25}$ suggest associations between the SADE and improved cooperation and relaxation in children with DD. 
There are two major clinical recommendations from our findings: (1) pre-appointment sensory/behavior assessment form reported by the parents and (2) tailoring the sensory modifications specific to the child's need based on the assessment. The pre-appointment sensory/behavior assessment will allow the practitioner to have a better understanding of the child's sensory responses. Based on this assessment, practitioners could modify the sensory environment to meet their specific sensory needs, thereby, identifying appropriate behavior guidance strategies for each patient.

Marshall et al. identified five potential risk factors for uncooperative behavior in a dental setting: (1) age, (2) ability to read, (3) toilet training, (4) concurrent diagnoses (ID, DD, seizure disorder, attention deficit/hyperactivity disorder, fragile $\mathrm{X}$ syndrome, obsessive compulsive disorder, sensory defensiveness disorder, cerebral palsy, and oppositional defiant disorder), and (5) expressive language. ${ }^{19}$ This study found that having two or more of these risk factors was strongly associated with uncooperative behavior ( $p$-value $<0.001)$. In our study, there was evidence of a difference in observer's Frankl scores based on the patient's age ( $p$-value $=$ $0.0841)$, communication skills $(p$-value $=0.045)$, and history of papoose board $(p$-value $=0.0314)$. Our participants with younger age, inability to communication, and a history of papoose board use scored lower on Frankl behavior scores. These risk factors can be also considered in each child's action plan for the following dental visit to better prepare the dental team for a successful dental visit. 


\section{Limitations}

There were five major limitations to this study: (1) demographics, (2) 3-month follow-up rate,

(3) physiological measurement, (4) inability to blind the raters to the treatment group, and (5) parental bias. To review, the first limitation in our study was sample demographics. The participant sample for the study only included individuals with DD receiving care at VCU Pediatric Dental clinic. This resulted in a limited sample size that may not reflect the general population. All the consented participants were encouraged to return for 3-month follow-up visit under SADE or RDE. Only 64\% returned for the Phase II visit, which limited the data analysis using paired Wilcoxon Rank Sum test. The recall fall-out may have been largely due to sickness in family members, weather issues, and conflicts with transportation.

Also, it was difficult to obtain physiological measurements from the study subjects. The amount of time it took to place the pulse oxygen sensor on each participant varied due to the participant cooperation. The goal of the physiological measurement for this study was to observe any difference in heart rate or in oxygen saturation level in subjects receiving dental care under SADE compared that of a RDE. Future study should account for this confounding factor by videotaping the entire appointment and observing the time it took for the pulse oximeter sensor.

Additionally, due to the nature of the study, we were not able to blind the raters as to how the dental environment was modified for the treatment group. The parents of the participants who completed the post-treatment survey were not blinded due to the same reason. Lastly, the 
parents' response to the post-treatment survey may be biased because since parents naturally want to see improvement in their child's behavior. The parents may have showed a strong agreement and satisfaction with the SADE for their child because they support and appreciate the goals of the study and the effort made in finding ways to improve the dental experience of children with DD. 


\section{Conclusion}

The SADE designed to modify sensory stimuli typically presented in a dental setting may be associated with improving dental experience of children with DD. It may be associated with minimizing the sensory stimuli and increasing relaxation of the children of DD receiving a routine dental care. Future research with a larger sample size is needed to examine the efficacy of individualized SADE based on each child's sensory/behavior assessment. 


\section{List of References}

1. Key Findings: Trends in the Prevalence of Developmental Disabilities in the U.S. Children, 1997-2008. 2016(09/16).

https://www.cdc.gov/ncbddd/developmentaldisabilities/features/birthdefects-ddkeyfindings.html.

2. American Psychiatric Association. Diagnostic and Statistical Manual of Mental Disorders. American Psychiatric Association; 2013. doi:10.1176/appi.books.9780890425596.

3. Owens PL, Kerker BD, Zigler E, Horwitz SM. Vision and oral health needs of individuals with intellectual disability. Ment Retard Dev Disabil Res Rev. 2006;12(1):28-40. doi:10.1002/mrdd.20096 [doi].

4. Mouradian WE, Corbin SB. Addressing health disparities through dental-medical collaborations, part II. Cross-cutting themes in the care of special populations. J Dent Educ. 2003;67(12):1320-1326. http://www.ncbi.nlm.nih.gov/pubmed/14733264. Accessed November 16, 2017.

5. Norwood KW, Slayton RL, Council on Children With Disabilities, Section on Oral Health. Oral Health Care for Children With Developmental Disabilities. Pediatrics. 2013;131(3):614-619. doi:10.1542/peds.2012-3650.

6. Nelson LP, Getzin A, Graham D, et al. Unmet dental needs and barriers to care for 
children with significant special health care needs. Pediatr Dent. 33(1):29-36. http://www.ncbi.nlm.nih.gov/pubmed/21406145. Accessed November 16, 2017.

7. Nowak AJ, Casamassimo PS, Slayton RL. Facilitating the transition of patients with special health care needs from pediatric to adult oral health care. J Am Dent Assoc. 2010;141(11):1351-1356. http://www.ncbi.nlm.nih.gov/pubmed/21037193. Accessed November 16, 2017.

8. Guideline on Management of Dental Patients with Special Health Care Needs. Ref Man Clin Pract Guidel. 2017;39:229-234.

http://www.aapd.org/media/Policies_Guidelines/G_SHCN1.pdf. Accessed February 22, 2018.

9. Brickhouse TH, Farrington FH, Best AM, Ellsworth CW. Barriers to dental care for children in Virginia with autism spectrum disorders. J Dent Child (Chic). 76(3):188-193. http://www.ncbi.nlm.nih.gov/pubmed/19941759. Accessed February 25, 2018.

10. Casamassimo PS, Seale NS, Ruehs K. General dentists' perceptions of educational and treatment issues affecting access to care for children with special health care needs. J Dent Educ. 2004;68(1):23-28. http://www.ncbi.nlm.nih.gov/pubmed/14761169. Accessed February 4, 2018.

11. Newacheck PW, McManus M, Fox HB, Hung YY, Halfon N. Access to health care for children with special health care needs. Pediatrics. 2000;105(4 Pt 1):760-766. http://www.ncbi.nlm.nih.gov/pubmed/10742317. Accessed February 13, 2018.

12. Krahn GL, Hammond L, Turner A. A cascade of disparities: health and health care access for people with intellectual disabilities. Ment Retard Dev Disabil Res Rev. 2006;12(1):7082. doi:10.1002/mrdd.20098. 
13. Fenton SJ, Hood H, Holder M, May PB, Mouradian WE. The American Academy of Developmental Medicine and Dentistry: eliminating health disparities for individuals with mental retardation and other developmental disabilities. J Dent Educ. 2003;67(12):13371344. http://www.ncbi.nlm.nih.gov/pubmed/14733266. Accessed November 16, 2017.

14. Stein LI, Polido JC, Mailloux Z, Coleman GG, Cermak SA. Oral care and sensory sensitivities in children with autism spectrum disorders. Spec Care Dentist. 2011;31(3):102-110. doi:10.1111/j.1754-4505.2011.00187.x.

15. Stein LI, Polido JC, Najera SOL, Cermak SA. Oral care experiences and challenges in children with autism spectrum disorders. Pediatr Dent. 34(5):387-391. http://www.ncbi.nlm.nih.gov/pubmed/23211914. Accessed February 22, 2018.

16. Stein LI, Polido JC, Cermak SA. Oral care and sensory over-responsivity in children with autism spectrum disorders. Pediatr Dent. 35(3):230-235.

http://www.ncbi.nlm.nih.gov/pubmed/23756306. Accessed January 17, 2018.

17. Shapiro M, Sgan-Cohen HD, Parush S, Melmed RN. Influence of adapted environment on the anxiety of medically treated children with developmental disability. J Pediatr. 2009;154(4):546-550. doi:10.1016/j.jpeds.2008.10.017 [doi].

18. Kuhaneck HM, Chisholm EC. Improving dental visits for individuals with autism spectrum disorders through an understanding of sensory processing. Spec Care Dentist. 2012;32(6):229-233. doi:10.1111/j.1754-4505.2012.00283.x [doi].

19. Marshall J, Sheller B, Williams BJ, Mancl L, Cowan C. Cooperation predictors for dental patients with autism. Pediatr Dent. 29(5):369-376.

http://www.ncbi.nlm.nih.gov/pubmed/18027770. Accessed February 13, 2018.

20. Ben-Sasson A, Hen L, Fluss R, Cermak SA, Engel-Yeger B, Gal E. A meta-analysis of 
sensory modulation symptoms in individuals with autism spectrum disorders. J Autism Dev Disord. 2009;39(1):1-11. doi:10.1007/s10803-008-0593-3.

21. Ayres AJ. Sensory Integration and the Child. Los Angeles: Western Psychological Services; 1979.

22. Barton EE, Reichow B, Schnitz A, Smith IC, Sherlock D. A systematic review of sensorybased treatments for children with disabilities. Res Dev Disabil. 2015;37:64-80. doi:10.1016/j.ridd.2014.11.006 [doi].

23. Shapiro M, Melmed RN, Sgan-Cohen HD, Eli I, Parush S. Behavioural and physiological effect of dental environment sensory adaptation on children's dental anxiety. Eur J Oral Sci. 2007;115(6):479-483. doi:EOS490 [pii].

24. Shapiro M, Melmed RN, Sgan-Cohen HD, Parush S. Effect of sensory adaptation on anxiety of children with developmental disabilities: a new approach. Pediatr Dent. 2009;31(3):222-228.

25. Cermak SA, Duker LIS, Williams ME, Dawson ME, Lane CJ, Polido JC. Sensory Adapted Dental Environments to Enhance Oral Care for Children with Autism Spectrum Disorders: A Randomized Controlled Pilot Study. J Autism Dev Disord. 2015;45(9):28762888. doi:10.1007/s10803-015-2450-5 [doi].

26. Edelson SM, Edelson MG, Kerr DC, Grandin T. Behavioral and physiological effects of deep pressure on children with autism: a pilot study evaluating the efficacy of Grandin's Hug Machine. Am J Occup Ther. 53(2):145-152. http://www.ncbi.nlm.nih.gov/pubmed/10200837. Accessed February 25, 2018.

27. Dunn W. Child Sensory Profile - 2 User's Manual. Bloomington, MN: Pearson; 2014. 28. Frankl, S. N., Shiere, F.R., Fogels HR. Should the parent remain with the child in the 
dental operatory. J Dent Child. 1962;29:150-163.

29. Aartman IHA, van Everdingen T, Hoogstraten J, Schuurs AHB. Appraisal of behavioral measurement techniques for assessing dental anxiety and fear in children: A review. $J$ Psychopathol Behav Assess. 1996;18(2):153-171. doi:10.1007/BF02229114.

30. Bodison SC, Parham LD. Specific Sensory Techniques and Sensory Environmental Modifications for Children and Youth With Sensory Integration Difficulties: A Systematic Review. Am J Occup Ther. 2017;72(1):7201190040p1-7201190040p11. doi:10.5014/ajot.2018.029413.

31. AAPD. Guideline on Behavior Guidance for the Pediatric Dental Patient. Ref Man Clin Pract Guidel. 2016;38(6):185-198. doi:10.1542/peds.2005-2315.

32. Schaaf RC, Dumont RL, Arbesman M, May-Benson TA. Efficacy of Occupational Therapy Using Ayres Sensory Integration ${ }^{\circledR}$ : A Systematic Review. Am J Occup Ther. 2017;72(1):7201190010p1. doi:10.5014/ajot.2018.028431.

33. Case-Smith J, Weaver LL, Fristad MA. A systematic review of sensory processing interventions for children with autism spectrum disorders. Autism. 2015;19(2):133-148. doi:10.1177/1362361313517762. 


\section{Appendix 1}

\section{Demographic Survey}

1. Please select gender of your child:
a. Male
b. Female
c. Other: (free text)

2. Please select age of your child:
a. 6-10 years old
b. 11-15 years old
c. 16-21 years old

3. Please select race/ethnicity of your child (Select all that apply):
a. American Indian or Alaska native
b. Asian
c. Black or African American
d. Hispanic or Latino
e. Native Hawaiian or Other Pacific Islander
f. White
g. Other

4. Please select primary diagnosis of your child (Select all that apply):
a. Intellectual Disability (Mental disability)
b. Autism Spectrum Disorder
c. Cerebral Palsy
d. Down Syndrome
e. Developmental Delay/Disability
f. Attention Deficit/Hyperactivity Disorder (ADHD)
g. Sensory Processing Disorder
h. Other: (free text)

5. Please select your level of education
a. Some high school
b. High school graduate
c. Associate degree
d. Some college
e. College graduate (bachelor's degree)
f. Master's degree
g. Professional degree
h. Doctoral degree 
Appendix 2

Post-Treatment Survey for Parents

\begin{tabular}{|c|c|c|c|c|c|}
\hline & $\begin{array}{l}\text { Strongly } \\
\text { Disagree }\end{array}$ & Disagree & Neutral & Agree & $\begin{array}{c}\text { Strongly } \\
\text { Agree }\end{array}$ \\
\hline $\begin{array}{l}\text { 1. The Sensory Adapted Dental } \\
\text { Environment (SADE) improved } \\
\text { my child's dental anxiety during } \\
\text { the routine dental exam and } \\
\text { cleaning. }\end{array}$ & & & & & \\
\hline $\begin{array}{l}\text { 2. The SADE improved my child's } \\
\text { cooperation for the routine } \\
\text { dental exam and cleaning. }\end{array}$ & & & & & \\
\hline $\begin{array}{l}\text { 3. My child did better cooperating } \\
\text { for dental exam and cleaning in } \\
\text { the SADE compared to his/her } \\
\text { previous dental exams and } \\
\text { cleanings. }\end{array}$ & & & & & \\
\hline $\begin{array}{l}\text { 4. I would prefer my child to } \\
\text { receive dental exam under } \\
\text { SADE instead of a regular dental } \\
\text { environment for my child's next } \\
\text { visit. }\end{array}$ & & & & & \\
\hline
\end{tabular}


Appendix 3

Sensory Adapted Dental Environment (SADE)
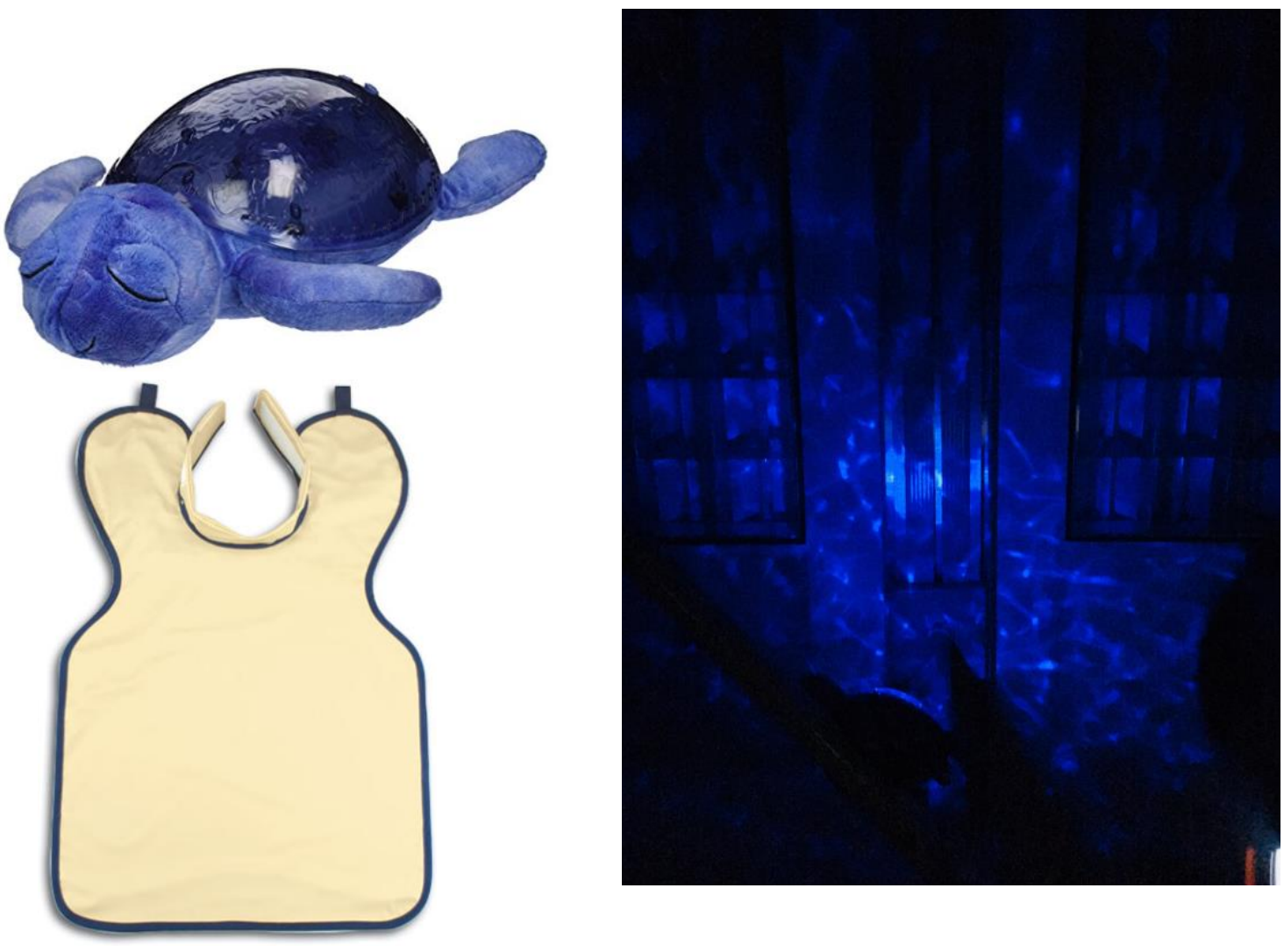
Appendix 4

Sensory Adapted Dental Environment

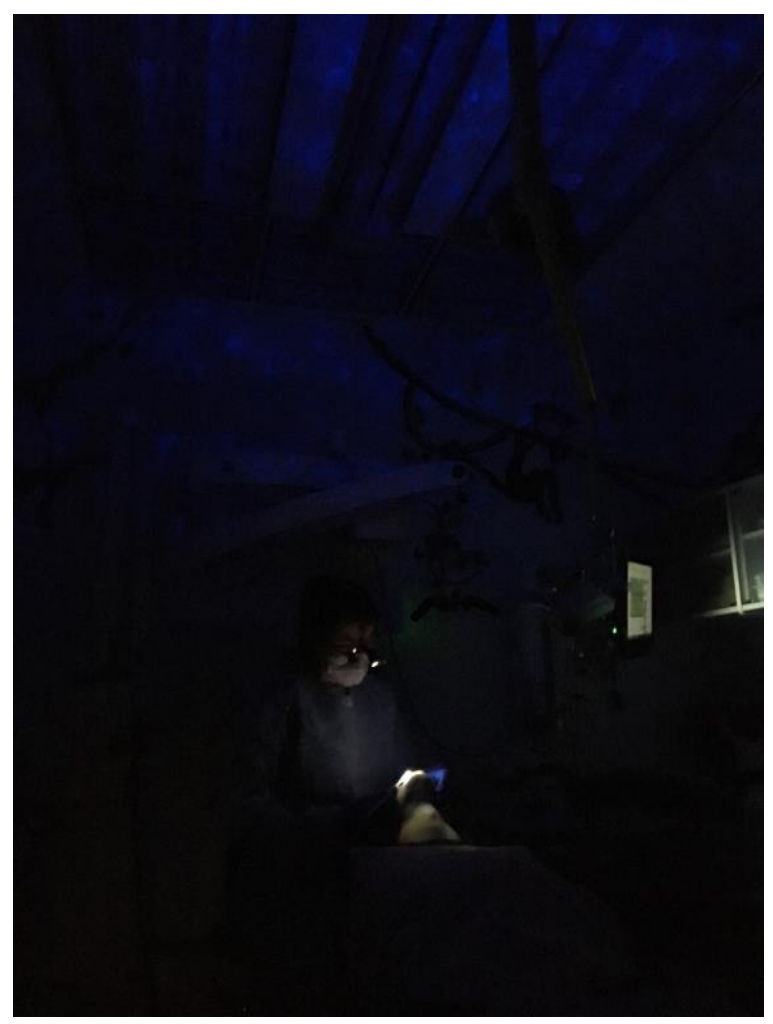

Regular Dental Environment

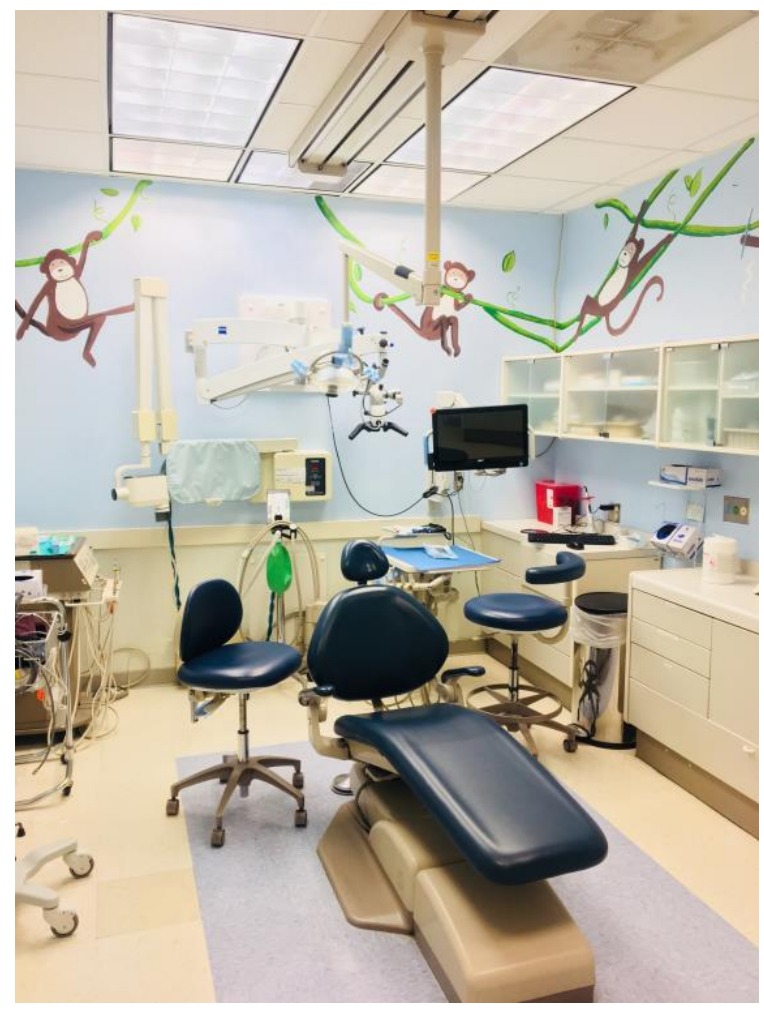

